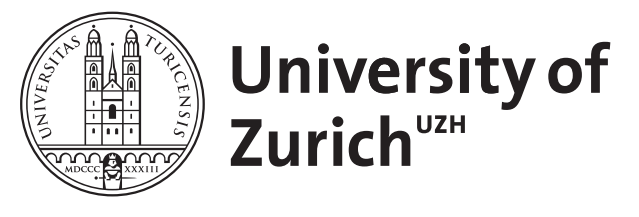

\title{
Global Burden of Stroke
}

\author{
Katan, Mira ; Luft, Andreas
}

\begin{abstract}
Stroke is the second leading cause of death and a major cause of disability worldwide. Its incidence is increasing because the population ages. In addition, more young people are affected by stroke in low- and middle-income countries. Ischemic stroke is more frequent but hemorrhagic stroke is responsible for more deaths and disability-adjusted life-years lost. Incidence and mortality of stroke differ between countries, geographical regions, and ethnic groups. In high-income countries mainly, improvements in prevention, acute treatment, and neurorehabilitation have led to a substantial decrease in the burden of stroke over the past 30 years. This article reviews the epidemiological and clinical data concerning stroke incidence and burden around the globe.
\end{abstract}

DOI: https://doi.org/10.1055/s-0038-1649503

Posted at the Zurich Open Repository and Archive, University of Zurich

ZORA URL: https://doi.org/10.5167/uzh-159894

Journal Article

Accepted Version

Originally published at:

Katan, Mira; Luft, Andreas (2018). Global Burden of Stroke. Seminars in Neurology, 38(2):208-211.

DOI: https://doi.org/10.1055/s-0038-1649503 


\section{Katan M and Luft A}

Full Title: Global burden of stroke

Authors:

Mira Katan, MD ${ }^{1}$, MS and Andreas Luft, MD ${ }^{1,2}$

${ }^{1}$ University Hospital of Zurich, Department of Neurology, Stroke Center, Zurich, Switzerland

2 cereneo Center for Neurology and Rehabilitation, Vitznau, Switzerland

Corresponding authors:

Andreas R. Luft, MD

Department of Neurology, University Hospital of Zurich

Frauenklinikstrasse 26, 8091 Zürich, Switzerland

Tel: +41 (0)44 2555400

E-mail: andreas.luft @usz.ch

Word count:

Referneces:

Key words: 


\section{Abstract}

Stroke is the second leading cause of death and a major cause of disability worldwide. Its indicence is increasing because the population ages. In addition, more young people are affected by stroke in low and middle income countries. Ischemic stroke is more frequent but hemorrhagic stroke is responsible for more deaths and disability adjusted life years lost. Incidence and mortality of stroke differ between countries, geographical regions and ethnic groups. In high income countries mainly, improvements in prevention, acute treatment and neurorehabilitation have lead to a substantial decrease in the burden of stroke over the past 30 years. This article reviews epidemiological and clinical data concerning stroke indicende and burden around the globe.

\section{Stroke burden, costs and disparities}

The latest estimate from the Global Burden of Disease, Injuries and Risk Factors Study (GBD 2015) revealed a further shift from communicable diseases, maternal and nutritional causes towards non-communicable diseases like stroke. This effect of likely caused by increase and aging of the world's population as well as by global decreased death rates in the last decades ${ }^{1}$. The most prominent causes of death are vascular in nature and stroke is currently still the second leading cause of death worldwide ${ }^{2}$. Ischaemic heart disease and stroke together accounted for $15 \cdot 2$ million deaths ( $15 \cdot 0$ million to $15 \cdot 6$ million) in $2015^{2}$.

Currently, approximately 3-4\% of total health care expenditures in Western countries are spent on stroke ${ }^{3}$. The mean lifetime cost of ischemic stroke per person, which includes inpatient care, rehabilitation, and follow-up care, is estimated at $\$ 140,048$ in the US 4 . 


\section{Katan $\mathrm{M}$ and Luft $\mathrm{A}$}

The total annual direct costs were estimated at $€ 26.6$ billion in 2010 for the EU plus Iceland, Norway, and Switzerland ${ }^{5}$. Inpatient hospital costs for acute stroke accounts for $70 \%$ of first-year post-stroke costs $^{6}$. Severe strokes (NIHSS >20) cost twice as much as mild strokes, despite similar diagnostic testing ${ }^{6}$. Comorbidities such as ischemic heart disease and atrial fibrillation predict higher costs ${ }^{6}$. The American Heart Association projects the total cost of stroke, which encompasses both direct and indirect spending, to increase from $\$ 105.2$ billion in 2012 to $\$ 240.7$ billion by $2030^{7}$. It is likely that estimates of morbidity and cost burden, based on traditional measures such as physical disability and healthcare costs, underestimate the burden of cerebrovascular disease. It is increasingly appreciated, for example, that subclinical cerebrovascular disease-including so-called silent infarction identified on brain imaging in $<=28 \%$ of the population aged $>65$ years $^{8}$ and ischemic white matter disease-is associated with memory loss, dementia, gait impairment, and other functional disability ${ }^{9}$.

Stroke is preventable to a large extent due to modifiable risk factors ${ }^{10}$. Targeting risk factors such as high blood pressure, smoking, obesity, diabetes mellitus, atrial fibrillation, dyslipidaemia and lack of physical activity may have already contributed to the observed improvement of stroke incidence, mortality and disability-adjusted life-years (DALYs) in highincome countries over the last two decades. However the absolute numbers of incidence stroke, survivors and stroke related death as well as DALYS lost has increased, partly due to the rising numbers in low and middle-income countries ${ }^{2}$.

While ischemic strokes comprise the highest number of stroke, most of the global burden of stroke measured in proportion to mortality and by DALYs is allocated to haemorrhagic stroke $^{11}$. Low and middle-income countries endure $80 \%$ of death due to haemorrhagic stroke ${ }^{11}$. 
The burden of stroke in people younger than 65 has increased over the last decades, the incidence has increased worldwide by $25 \%$ among adults age 20 to 64 . There is a concerning shift of the overall stroke burden towards younger age groups, particularly in low and middleincome countries. The epidemic rise in cardiovascular risk factors in young adults in some regions such as Russia, China as well as India has contributed to the increase in stroke burden among the younger population ${ }^{12-17}$. Stroke is an especially serious problem in Asia, which has more than $60 \%$ of the world's population, and many of its countries are "developing" economies. Stroke mortality is higher in Asia than in Western Europe, the Americas or Australasia, similar to Eastern Europe ${ }^{18}$.

Besides geographical disparities there are also clear disparities between different race and ethnic groups. For example there is an (200-300\%) excess mortality for blacks age 45 to 65 compared to the withe population in the $\mathrm{US}^{19-21}$. About $50 \%$ of this excess is explained by traditional risk factors mainly hypertension as well as differences in socio-economic status, highlighting the importance of stroke prevention interventions aimed at minority groups ${ }^{22}$. Inequality in stroke mortality is also observed in women compared to men in many regions around the globe ${ }^{1}$. The WHO reported an excess of total stroke-related deaths among women compared with men between 1990 and 2006, of which 60\% occurred in those aged over 75 years $^{23}$. A study performed in 8 different European countries found that the risk of stroke increased by $9 \%$ per year in men and $10 \%$ per year in women ${ }^{24}$. This excess risk may be partly explained by the longer life span of women compared with men and by the fact that hypertension and atrial fibrillation, key risk factors for stroke, are more frequent in women than in men ${ }^{25}$. But further differences in vascular biology, immunity, coagulation, hormonal profiles, life style 


\section{Katan $\mathrm{M}$ and Luft $\mathrm{A}$}

factors and societal roles seem to contribute, especially due to risks related to pregnancy and the postpartum state ${ }^{25}$.

In conclusion in high income countries a substantial decrease of stroke incidence, mortality and disability-adjusted life-years (DALYs) has been achieved in the last decades, most likely due to improvement in primary and secondary prevention as well as acute stroke treamtment and neurorehabilitation. However, stroke remains an important cause of disability and death worldwide. Globally, the burden of stroke has increased substantially over the past decades because of expanding population numbers and ageing as well as increased prevalence of many modifiable stroke risk factors especially in low and middle income countires. The number of patients who will need care by clinicians with expertise in neurological conditions will continue to grow in coming decades ${ }^{2}$.

\section{Stroke etiology and secondary prevention}

At least one stroke survivor out of six will suffer another stroke within 5 years ${ }^{26}$. To prevent stroke recurrence patients are treated based on the presumed underlying etiology. Patients with symptomatic high-grade carotid stenosis undergo carotid endarterectomy or stenting, patients with cardioembolic infarcts due to atrial fibrillation are treated with oral anticoagulants and patients with infective endocarditis are treated with antibiotics. But how do we identify the underlying cause?

Various stroke etiologic classification systems have been developed. The TOAST 2 classification system is the most commonly used in patients with ischemic stroke. By means of clinical judgment applied to results of the patient's neurological exam, brain imaging (CT/MRI), 
standard 24-hour electrocardiography, echocardiography and ultrasound of extra and intracranial arteries, the most likely etiology is determined. Specifically, the TOAST system classifies ischemic strokes as due to large-vessel atherosclerosis, cardioembolic source, small vessel disease, other "determined" causes, and stroke of "undetermined" etiology ${ }^{27}$. The last mentioned category comprises also those patients without known cause due to incomplete evaluation or due to the occurrence of multiple competing causes.

Other somewhat newer sub-classification systems, the Causative Classification of Stroke (CCS) system ${ }^{28}$ and the A-S-C-O classification ${ }^{29}$ are also available. The CSS system is advancing the accuracy of ischemic stroke subtype diagnosis by taking into account the level of diagnostic evidence in order to devise the "most likely mechanism" in the presence of multiple potential causes. The process goes beyond the results of etiologic testing and basically standardizes the clinical decision-making process, replacing an algorithm for the individual clinician's judgment, to arrive at the cause of the stroke. The A-S-C-O classification system does not determine a final stroke etiology per se but rather takes into account the combination of all potential mechanisms graded by their impact, thus this approach is more descriptive, or phenotypic.

Despite the fact that the newer classification systems may have better discriminatory value, in clinical practice we are unable to identify the underlying cause with reasonable certainty in up to $30 \%$ of patients ${ }^{30}$. Thus in these patients secondary prevention cannot be tailored towards the underlying etiology and the relative benefits of antiplatelet and anticoagulant therapy remain uncertain ${ }^{31}$.

To address part of this problem recently a group of scientists suggested defining a new entity within the "undetermined" category and they called it embolic stroke of undetermined source 


\section{Katan $\mathrm{M}$ and Luft $\mathrm{A}$}

$(\text { ESUS })^{30}$ if even after extensive evaluation no underlying cause can be identified. They proposed that most of these types of stroke are of an embolic nature.

Diverse low-risk sources are the presumed origin of thromboemboli causing infarcts in embolic strokes of undetermined source, including, low-burden or undetected paroxysmal atrial fibrillation, patent foramen ovale, mild left ventricular dysfunction, aortic-arch atherosclerosis, and nonstenosing atherosclerotic plaques in cervical and intracranial arteries ${ }^{31}$. Currently there are two trials ongoing (RESPECT ESUS and ATTICUS), one was terminated early for futility (NAVIGATE ESUS), which aim to prove that all these patients might benefit from the novel anticoagulants.

But then again how well do old and newer stroke classification schemes measure up to recent advances in precision medicine? Blood biomarkers, for example may provide additional insight into stroke etiology. Distinct gene expression profiles were able to accurately differentiate stroke patients with atrial fibrillation from patients with large artery stenosis ${ }^{32}$. Several studies have confirmed that natriuretic peptides, mainly N-terminal brain natriuretic peptide (NT-proBNP) ${ }^{33}$ and mid-regional atrial natriuretic peptide (MRproANP) ${ }^{34}$ are able to identify primarily cardioembolic stroke subtypes as well as stroke risk. In addition higher NTproBNP levels were associated with a relative benefit of warfarin compared with aspirin for prevention of recurrent stroke $\mathrm{e}^{35}$.

If confirmed in randomized controlled trials blood biomarkers may help in detecting underlying etiology and thus guide secondary prevention ${ }^{36}$.

\section{Disability rehabilitation and socioeconomic burden}

Stroke is the leading cause of long-term disability in the US especially in the elderly population in which stroke incidence is highest. From the 795000 new sufferes of a stroke, 26\% remain 
disabled in basic activities of daily living (Framingham cohort) and 50\% have reduced mobility due to hemiparesis ${ }^{37}$. Aphasia and depression are other frequent causes for disability ${ }^{37}$. In the US, stroke is third in disability and socioeconomic impact (direct and indirect cost) after back pain and osteoarthritis. It causes total direct costs of 20-30 billion USD and indirect costs of 1525 billion USD ${ }^{38}$. Costs depend on the level of disability and are generally higher for hemorrhagic as compared with ischemic stroke ${ }^{39}$ as is the loss in disability adjusted life years $(\mathrm{DALY})^{40}$.

The global burden of disease study 2013 found an increase in stroke incidence and DALYs in younger adults aged 20-64 years. This increase was most prevalent in developing contries and more due to hemorrhagic than ischemic stroke ${ }^{41}$. Stoke burdens clearly is a function of socioeconomic status with greater odds of disability in patients with lower education and income 42.

Evidence that specialized stroke rehabilitation reduces long term disability and stroke-related costs exists for different contries and health care systems including Switzerland ${ }^{43}, \mathrm{UK}^{44,45}$ and Japan $^{46}$. Cost effectiveness depends on the severity of disability: patients with moderate disability benefit more than those with severe or mild stroke severity ${ }^{46}$.

\section{Disclosures:}

None relevant for this manuscript.

\section{References}




\section{Katan M and Luft A}

1. Mortality GBD, Causes of Death C. Global, regional, and national life expectancy, allcause mortality, and cause-specific mortality for 249 causes of death, 1980-2015: A systematic analysis for the global burden of disease study 2015. Lancet. 2016;388:14591544

2. Group GBDNDC. Global, regional, and national burden of neurological disorders during 1990-2015: A systematic analysis for the global burden of disease study 2015. Lancet Neurol. 2017;16:877-897

3. Struijs JN, van Genugten ML, Evers SM, Ament AJ, Baan CA, van den Bos GA. Future costs of stroke in the netherlands: The impact of stroke services. Int J Technol Assess Health Care. 2006;22:518-524

4. Johnson BH, Bonafede MM, Watson C. Short- and longer-term health-care resource utilization and costs associated with acute ischemic stroke. Clinicoecon Outcomes Res. 2016;8:53-61

5. Gustavsson A, Svensson M, Jacobi F, Allgulander C, Alonso J, Beghi E, et al. Cost of disorders of the brain in europe 2010. Eur Neuropsychopharmacol. 2011;21:718-779

6. Go AS, Mozaffarian D, Roger VL, Benjamin EJ, Berry JD, Blaha MJ, et al. Heart disease and stroke statistics--2014 update: A report from the american heart association. Circulation. 2014;129:e28-e292

7. Ovbiagele B, Goldstein LB, Higashida RT, Howard VJ, Johnston SC, Khavjou OA, et al. Forecasting the future of stroke in the united states: A policy statement from the american heart association and american stroke association. Stroke. 2013;44:2361-2375

8. Vermeer SE, Longstreth WT, Jr., Koudstaal PJ. Silent brain infarcts: A systematic review. Lancet Neurol. 2007;6:611-619

9. Boehme AK, Esenwa C, Elkind MS. Stroke risk factors, genetics, and prevention. Circ Res. 2017;120:472-495

10. O'Donnell MJ, Xavier D, Liu L, Zhang H, Chin SL, Rao-Melacini P, et al. Risk factors for ischaemic and intracerebral haemorrhagic stroke in 22 countries (the interstroke study): A case-control study. Lancet. 2010;376:112-123

11. Feigin VL, Norrving B, Mensah GA. Global burden of stroke. Circ Res. 2017;120:439-448

12. Danaei G, Finucane MM, Lin JK, Singh GM, Paciorek CJ, Cowan MJ, et al. National, regional, and global trends in systolic blood pressure since 1980: Systematic analysis of health examination surveys and epidemiological studies with 786 country-years and 5.4 million participants. Lancet. 2011;377:568-577

13. Norrving B, Kissela B. The global burden of stroke and need for a continuum of care. Neurology. 2013;80:S5-12

14. de los Rios F, Kleindorfer DO, Khoury J, Broderick JP, Moomaw CJ, Adeoye O, et al. Trends in substance abuse preceding stroke among young adults: A population-based study. Stroke. 2012;43:3179-3183

15. Zaridze D, Brennan P, Boreham J, Boroda A, Karpov R, Lazarev A, et al. Alcohol and causespecific mortality in russia: A retrospective case-control study of 48,557 adult deaths. Lancet. 2009;373:2201-2214

16. Hu SS, Kong LZ, Gao RL, Zhu ML, Wang W, Wang YJ, et al. Outline of the report on cardiovascular disease in china, 2010. Biomed Environ Sci. 2012;25:251-256 
17. Jha P, Jacob B, Gajalakshmi V, Gupta PC, Dhingra N, Kumar R, et al. A nationally representative case-control study of smoking and death in india. $N$ Engl J Med. 2008;358:1137-1147

18. Venketasubramanian N, Yoon BW, Pandian J, Navarro JC. Stroke epidemiology in south, east, and south-east asia: A review. J Stroke. 2017;19:286-294

19. Murray CJ, Atkinson C, Bhalla K, Birbeck G, Burstein R, Chou D, et al. The state of us health, 1990-2010: Burden of diseases, injuries, and risk factors. JAMA. 2013;310:591608

20. Writing Group M, Mozaffarian D, Benjamin EJ, Go AS, Arnett DK, Blaha MJ, et al. Heart disease and stroke statistics-2016 update: A report from the american heart association. Circulation. 2016;133:e38-360

21. Kissela BM, Khoury JC, Alwell K, Moomaw CJ, Woo D, Adeoye O, et al. Age at stroke: Temporal trends in stroke incidence in a large, biracial population. Neurology. 2012;79:1781-1787

22. Howard G, Prineas R, Moy C, Cushman M, Kellum M, Temple E, et al. Racial and geographic differences in awareness, treatment, and control of hypertension: The reasons for geographic and racial differences in stroke study. Stroke. 2006;37:1171-1178

23. Redon J, Olsen MH, Cooper RS, Zurriaga O, Martinez-Beneito MA, Laurent S, et al. Stroke mortality and trends from 1990 to 2006 in 39 countries from europe and central asia: Implications for control of high blood pressure. Eur Heart J. 2011;32:1424-1431

24. Asplund K, Karvanen J, Giampaoli S, Jousilahti P, Niemela M, Broda G, et al. Relative risks for stroke by age, sex, and population based on follow-up of 18 european populations in the morgam project. Stroke. 2009;40:2319-2326

25. Cordonnier C, Sprigg N, Sandset EC, Pavlovic A, Sunnerhagen KS, Caso V, et al. Stroke in women - from evidence to inequalities. Nat Rev Neurol. 2017;13:521-532

26. Benjamin EJ, Blaha MJ, Chiuve SE, Cushman M, Das SR, Deo R, et al. Heart disease and stroke statistics-2017 update: A report from the american heart association. Circulation. 2017;135:e146-e603

27. Adams HP, Jr., Bendixen BH, Kappelle LJ, Biller J, Love BB, Gordon DL, et al. Classification of subtype of acute ischemic stroke. Definitions for use in a multicenter clinical trial. Toast. Trial of org 10172 in acute stroke treatment. Stroke. 1993;24:35-41

28. Ay H, Benner T, Arsava EM, Furie KL, Singhal AB, Jensen MB, et al. A computerized algorithm for etiologic classification of ischemic stroke: The causative classification of stroke system. Stroke; a journal of cerebral circulation. 2007;38:2979-2984

29. Amarenco P, Bogousslavsky J, Caplan LR, Donnan GA, Hennerici MG. New approach to stroke subtyping: The a-s-c-o (phenotypic) classification of stroke. Cerebrovascular diseases. 2009;27:502-508

30. Hart RG, Diener HC, Coutts SB, Easton JD, Granger CB, O'Donnell MJ, et al. Embolic strokes of undetermined source: The case for a new clinical construct. The Lancet. Neurology. 2014;13:429-438

31. Saver JL. Clinical practice. Cryptogenic stroke. N Engl J Med. 2016;374:2065-2074

32. Jickling GC, Xu H, Stamova B, Ander BP, Zhan X, Tian Y, et al. Signatures of cardioembolic and large-vessel ischemic stroke. Annals of neurology. 2010;68:681-692 
33. Llombart V, Antolin-Fontes A, Bustamante A, Giralt D, Rost NS, Furie K, et al. B-type natriuretic peptides help in cardioembolic stroke diagnosis: Pooled data meta-analysis. Stroke. 2015;46:1187-1195

34. Katan M., Fluri F., Schuetz P., Morgenthaler N.G., Zweifel Ch., Bingisser R., et al. Midregional pro-atrial natriuretic peptide and outcome in patients with acute ischemic stroke Journal of American College of Cardiology. 2010;56:1045-1053

35. Longstreth WT, Jr., Kronmal RA, Thompson JL, Christenson RH, Levine SR, Gross R, et al. Amino terminal pro-b-type natriuretic peptide, secondary stroke prevention, and choice of antithrombotic therapy. Stroke. 2013;44:714-719

36. Elkind MS. Stroke etiologic classification-moving from prediction to precision. JAMA Neurol. 2017;74:388-390

37. Kelly-Hayes M, Beiser A, Kase CS, Scaramucci A, D'Agostino RB, Wolf PA. The influence of gender and age on disability following ischemic stroke: The framingham study. Journal of Stroke and Cerebrovascular Diseases. 2003;12:119-126

38. Ma VY, Chan L, Carruthers KJ. Incidence, prevalence, costs, and impact on disability of common conditions requiring rehabilitation in the united states: Stroke, spinal cord injury, traumatic brain injury, multiple sclerosis, osteoarthritis, rheumatoid arthritis, limb loss, and back pain. Archives of Physical Medicine and Rehabilitation. 2014;95:986-9950

39. Lekander I, Willers C, von Euler M, Lilja M, Sunnerhagen KS, Pessah-Rasmussen H, et al. Relationship between functional disability and costs one and two years post stroke. PLOS ONE. 2017;12

40. Barker-Collo S, Bennett DA, Krishnamurthi RV, Parmar P, Feigin VL, Naghavi M, et al. Sex differences in stroke incidence, prevalence, mortality and disability-adjusted life years: Results from the global burden of disease study 2013. Neuroepidemiology. 2015;45:203214

41. Krishnamurthi RV, Moran AE, Feigin VL, Barker-Collo S, Norrving B, Mensah GA, et al. Stroke prevalence, mortality and disability-adjusted life years in adults aged 20-64 years in 1990-2013: Data from the global burden of disease 2013 study. Neuroepidemiology. 2015;45:190-202

42. Bettger J, Zhao X, Bushnell C, Zimmer L, Pan W, Williams LS, et al. The association between socioeconomic status and disability after stroke: Findings from the adherence evaluation after ischemic stroke longitudinal (avail) registry. BMC Public Health. 2014;14:1-8

43. Mahler MP, Züger K, Kaspar K, Haefeli A, Jenni W, Leniger T, et al. A cost analysis of the first year after stroke - early triage and inpatient rehabilitation may reduce long term costs. Swiss medical weekly. 2008;138:459-465

44. O'Connor RJ, Beden R, Pilling A, Chamberlain AM. What reductions in dependency costs result from treatment in an inpatient neurological rehabilitation unit for people with stroke? Clinical Medicine. 2011;11:40-43

45. Turner-Stokes L, Williams H, Bill A, Bassett P, Sephton K. Cost-efficiency of specialist inpatient rehabilitation for working-aged adults with complex neurological disabilities: $A$ multicentre cohort analysis of a national clinical data set. BMJ Open. 2016;6

46. Murata K, Hinotsu S, Sadamasa N, Yoshida K, Sen Y, Asari S, et al. Healthcare resource utilization and clinical outcomes associated with acute care and inpatient rehabilitation 
of stroke patients in japan. International journal for quality in health care : journal of the International Society for Quality in Health Care. 2016 